\title{
Prevalence of Psychological Distress and Mental Health Problems among the Survivors in the Flash Floods and Landslide in Southern Thailand
}

\author{
Jiraporn SONPAVEERAWONG ${ }^{1, *}$, Wanida LIMMUN ${ }^{2}$ and \\ Nidarat CHUWICHIAN ${ }^{1}$
}

${ }^{1}$ School of Nursing, Walailak University, Nakhon Si Thammarat 80161, Thailand
${ }^{2}$ School of Science, Walailak University, Nakhon Si Thammarat 80161, Thailand

('Corresponding author's e-mail: jiraporns@gmail.com)

Received: 28 May 2017, Revised: 31 October 2017, Accepted: 19 November 2017

\begin{abstract}
Significant evidence has shown that southern Thailand is prone to the highest risk of repeated flooding. However, psychological distress and mental health problems caused by the flash floods and landslides have been under-researched among Thai survivors. This cross-sectional study aimed to explore characteristics and factors associated with the prevalence of psychological distress, probable post traumatic stress disorder (PTSD), probable depression, suicide risk, and alcohol problems 4 to 6 months after the flooding. The research examined 326 survivors from households in flooded communities in Nakhon Si Thammarat province during 2011. Descriptive statistics, correlation analysis and a binary logistic regression model were applied to the data representing demographics, household damage, perceived mental health impact, social support and mental health problems. The results showed that the prevalence rate of probable PTSD, probable depression, psychological distress, suicide risk, and alcohol problems were 44.48, 31.29, 29.45, 17.18 and $4.60 \%$, respectively. Risk factors that variously affected those mental health problems were age, gender, prior physical condition, perception of mental health impacts, skin infection, and injury incurred during the flood. On the other hand, a significant protective factor was the degree of social support. Results suggest that rapid actions should be taken immediately after flooding, especially management with the risk survivor group and promotion of social support to minimize the mental health impacts associated with the flooding.
\end{abstract}

Keywords: Mental health, PTSD, depression, suicide, floods, Thailand

\section{Introduction}

Floods are a most common disaster negatively impacting the mental health of the survivors [1-7] with both short-term and long-term consequences. It is also predicted that the occurrence of flooding will continue to increase in loss and damage around the world in the decades to come [8-10] from both the impact of natural and human causes. At the same time, evidence has shown that major psychological impacts or mental health problems from flooding are psychological distress, anxiety [11-13], posttraumatic stress disorder, depression and suicide [1,4,11,14-17] and alcohol problems [18,19]. Factors affecting the prevalence of psychological distress and mental health problems included pre-existing mental health problems [11,20], socio-economic factors and flood severity [11,16,20,21]. While risk factors for poorer mental health status following flooding included being of female gender [11,20], older in age [11,22] lower educational achievement [11,20], lower household income [11,20,22], long term health problems and less social support [11]. Thailand has been faced with flood disasters for several decades, especially in Southern Thailand. The causes of flooding were not only heavy rainfalls during the 
rainy season or storms, but also rapid transformation of landscape due to misuse and deforestation. The evidence from a research study using Geographic Information Systems (GIS) to predict the risk of flooding has shown that Nakhon Si Thammarat province has the highest risk in Southern Thailand [23]. This province occupies 1,437 square kilometers, comprising $14.4 \%$ of the total of all land in Thailand which is at risk of flooding [23].

In the summer of 2011, Thailand was faced with many floods in numerous areas of the country with the most severe flooding in 5 decades. One of the hardest hit areas by sudden flash floods and landslides was Nakhon Si Thammarat province, and also 10 other provinces in Southern Thailand resulting in flooding in 651 sub-districts, 100 districts in 10 provinces. By the end of April 2011, there were $2,094,595$ individuals from 628,998 families affected by this disaster with 813 houses fully damaged and 16,664 partially damaged [24]. The number of deaths from the floods reached 64 [24]. There were many flood-affected areas with Sichon subdistrict, Nakhon Si Thammarat province, Thailand being one of the first and mostly heavily hit localities with major flooding and landslides. A large number of primary and secondary roads in the communities were left impassable from soil, mud, rocks and branches carried by landslides from the mountains near the villages. Branches of rubber, palm and orchard trees from the mountain slid down and obstructed roads and rivers. Mud, rocks, and branches also destroyed entire houses or parts of houses and other property. Some villagers were trapped in their homes and also in their orchards and rubber plantations on the mountains. The residents suffered from a lack of access to clean water, electricity, transportation, healthcare, education, social services and deprivation of livelihood. This area also had been shown by using remote sensing and geographic information system in previous research studies to be highly susceptible to repeated flooding [25].

Evidence from the literature reviewed shows that there are various factors which may influence the psychological impact from disasters both factors of pre-existing conditions, such as survivor characteristics and also post-flood factors. The first pre-existing factor was gender. Many studies have found that the women tended to have a higher prevalence rate of probable post traumatic stress disorder (PTSD), anxiety and depression than the men [1,10,26,27], but gender was found to have had no relationship to long-term psychosocial impact [21]. The second factor considered was age. A study of a Chinese population found that elderly individuals had a higher predisposition towards PTSD [27]. In addition, a systematic review and meta-analysis study found that older adults were 2.11 times more likely to experience PTSD symptoms and 1.73 more likely to develop adjustment disorder when exposed to natural disasters compared with younger adults. However, some systematic reviews found contradictory evidence regarding the effect of gender and age [4]. The third factor considered was the socioeconomic status. It has been found that lower socioeconomic status has been associated with poorer mental health outcomes after exposure to floods [4,11,21]. Furthermore, existing physical and mental health problems before a flood were associated with poorer mental health outcomes after the flood [4,11]. However, the study by Zhou et al. found that the health condition before an earthquake showed no statistical significance when assessed after such an occurrence [27].

Post-flood factors included loss/damage and injuries resulting from the flood, lack of social support, and perception of adverse impact of the flood and perceived causes of the flood. The study of risk factors of PTSD among adult survivors 6 months after an earthquake in China found that the prevalence of PTSD was higher in survivors who were injured or witnessed someone being injured or dying in the earthquake [27]. For social support, a systematic review by Fernandez et al. found that social support had an inverse association with mental distress [4] and Zhang et al. also found social support had significant positive effects in mitigating PTSD, anxiety and depression [1]. Lastly, as for the perception of the impact of flooding, Fernandez et al. summarized from their systematic reviews that positive and proactive behaviors were associated with positive mental wellbeing [4].

Even though there have been many floods in Thailand, their prevalence and factors affecting their short-term impact on the psychological and mental health problems of Thai survivors have remained under-researched. The objectives of this study were to investigate the prevalence and factors contributing to the psychological distress and mental health problems of flashflood and landslide survivors 4 to 6 months after these disasters. This study adds knowledge and understanding of those factors related to specific mental health problems so that healthcare teams may be better able to prioritize and specify 
appropriate interventions to reduce risk and provide good outcomes according to the urgent needs of the survivors.

\section{Materials and methods}

The data in this study were from a research project titled "Health status, perceptions, adaptations and social support among people in flashfloods and mudslides in Sichon District, Nakhon Si Thammarat province, Thailand" and a part of this research project was published elsewhere [28]. This cross-sectional study was conducted between July and September 2011, 4 to 6 months after the flooding. The setting was in the flash flood areas located in Tepparat and Chalong subdistricts, Sichon district, Nakhon Si Thammarat province, Thailand. These areas were chosen as the staff working in the local health centers and the local community leaders identified that these areas were the hardest hit by the flash floods and landslides. The total numbers of households located in the hard-hit area were 340, however some of the people were not at home during the data collection. Due to the damage, we were able to collect data from 326 homes which were considered as basic samples where only one member per household was chosen to represent the unit. Participants were at least 20 years old and had to have directly experienced the flooding. Individuals who suffered from mental disabilities or major mental health problems were excluded from the sample. Ethics approval for this study was obtained from the Ethics Committee of Walailak University. Data collection was conducted anonymously with door-to-door and self-reporting methods. Researchers visited each participant's house, introduced the study, obtained written consent, distributed the questionnaire, and were present during data collection to answer any questions regarding the questionnaire. Participants with limited reading and writing abilities were read and explained the questionnaire by the researchers. Questionnaires were collected and immediately checked for completeness. If participants became distressed during the visit, the survey would be suspended and the researchers would use basic psychological intervention skills to provide support and recommended those individuals to the local health center in the community for advanced intervention. A total of 326 participants were included in this study.

The research tools consisted of 3 parts: Part I was composed of demographic questions including family data such as gender, age, marital status, educational level, religious beliefs, occupation, selfperception of health status prior to the flood, self-perception of current health status, medical problems before the flood, and house damage from the floods. Part II of the questionnaire included self-perception of psychological, social, and spiritual impact, adaptation and social support provided. Part III mainly measured short term psychological impact and mental health problems covered in the General Health Questionnaire Twelve Plus R (GHQ-12-Plus-R). The reliability of questionnaires were evaluated using Cronbach's alpha coefficient with an alpha of 0.85 for the perception of psychological, social and spiritual impact questionnaire, 0.60 for the perception and adaptation of people who were impacted by the disaster questionnaire, and 0.86 for the perceived receive of social support questionnaire. The third part of the questionnaire, the GHQ-12-Plus-R, has been used extensively as a screening instrument to detect individuals who are prone to having mental health problems in general or in a medical outpatient setting. It is self-reporting and has been used in previous studies with Thai survivors from both natural and human made disasters [2,29]. Item numbers 1 to 12 have been used for psychological distress screening. The total score is 12 and a score of 2 and above means that the individual has psychological distress or some mental health problems after the flooding. In our study, the cut-off score of 2 and above was used because the time of this study was during the rehabilitation phase; if the individual scored from 2 or higher, it meant the individual needed help from health providers. A higher score was an indicator of greater problems. The Cronbach alpha coefficient of the GHQ-12 was 0.80. Item numbers 13 to 20 were used to screen for PTSD which was indicated by a score of 4 and above. The Cronbach alpha coefficient of the PTSD questionnaire was 0.78 . Item number 21 was asked in order to determine thoughts of suicide. The last part of GHQ-12 plus-R consisted of 5 questions that screened for problems of alcohol misuse after the floods. The Cronbach alpha coefficient of the portion of the questionnaire dealing with alcohol was 0.71. A score of 2 and above meant there was a problem related to alcohol. The last portion of the questionnaire is the DS8, which is used to screen for depression and the risk of suicide. The Cronbach alpha coefficient 
for the DS8 segment of the questionnaire was 0.77 . The first 6 items were used to screen for depression with a score of 3 to 6 tentatively indicating depression. The last 2 items were used to screen for suicidal tendency. A score of 1 to 2 suggests a risk of suicide.

\section{Data analysis}

Descriptive statistics were computed for demographic characteristics, health status and physical condition prior to and post flood, physical trauma and injury during the flood, house and property damage, perception of flood impact to individual in 3 aspects (psychological, social, and spiritual), social support, and prevalence of psychological distress, PTSD, depression, suicide risk, and problems with alcohol. Binary logistic regression analyses identified the independent role of each risk factor for psychological distress and 4 mental health problems. All of the variables that were statistically significant $(\mathrm{p}<0.05)$ in the binary analyses were included in the multivariate model.

\section{Results and discussion}

\section{Results}

A total of 326 participants completed the self-administered questionnaires $(\operatorname{men}=177$, women $=$ 149). Participant ages ranged from 20 to 84 years, and the mean age was 44.44 years $(\mathrm{SD}=13.15)$. All participants were Buddhists, most were married $(85.90 \%)$, more than half had graduated from primary school $(56.1 \%)$, and most were rubber tappers $(88.70 \%)$. Income ranged from $15.30-1,835.98$ US dollars per month and the average income was 391.58 \pm 285.82 US dollars per month. More than half of them reported being in good health (54\%). Almost half of the participants had orchard damage $(49.10 \%)$ and rubber plant damage (39\%). Almost one in 5 had their whole house damaged (22.40\%). However, most participants were not injured from the floods (96.30).

Descriptive statistics and correlation analyses of probable PTSD, probable depression, psychological distress, alcohol abuse and risk of suicide are presented in Table 1. The results indicate that there are significant correlations among probable PTSD, probable depression, psychological distress and risk of suicide, suggesting that the occurrence of probable PTSD among flood and landslide survivors is concomitant with probable depression, psychological distress and risk of suicide. The prevalence rate of probable PTSD was $44.48 \%(n=145)$ based on the GHQ-12 plus R question number 13 to 20 cut-off score of 4 . The prevalence of probable depression was $31.29 \%(n=102)$ based on the DS8 cut-off score of 3 . The prevalence rate of psychological distress was $29.45 \%(n=96)$ based on the GHQ-12 plus R cut-off score of 2 . The prevalence of alcohol abuse was $17.18 \%(\mathrm{n}=56)$ based on the last 5 questions of the GHQ-12 plus-R cut-off score of 2 . The prevalence rate of individuals who were at risk for suicide was $4.60 \%(n=15)$ based on the last 2 items of DS8 cut-off score of 1 as shown in Table 2.

Table 1 Descriptive statistics and correlation of probable PTSD, probable depression, psychological distress, alcohol abuse and suicide risk $(\mathrm{N}=326)$.

\begin{tabular}{lccccccccc}
\hline & $\begin{array}{c}\text { Mean } \\
\text { (Total) }\end{array}$ & $\begin{array}{c}\text { SD } \\
\text { (Total) }\end{array}$ & Mean & SD & $\mathbf{1}$ & $\mathbf{2}$ & $\mathbf{3}$ & $\mathbf{4}$ & $\mathbf{5}$ \\
\hline 1. Probable PTSD & 2.95 & 2.33 & 5.15 & 1.32 & 1 & & & \\
2. Probable depression & 1.68 & 1.75 & 3.90 & 1.04 & $0.42^{*}$ & 1 & & & \\
3. Psychological distress & 1.54 & 2.45 & 4.61 & 2.55 & $.03 *$ & $.39^{*}$ & 1 & & \\
4. Alcohol abuse & 0.53 & 1.07 & 2.57 & 0.99 & -0.80 & -0.03 & -0.08 & 1 & \\
5. Risk of suicide & 0.05 & 0.21 & 1.30 & 0.48 & $0.18^{*}$ & $0.23^{*}$ & $0.24^{*}$ & 0.016 & 1 \\
\hline
\end{tabular}

$* p<0.05$ 
Table 2 Prevalence rate (\%) of probable PTSD, probable depression, psychological distress, alcohol abuse and suicide risk $(\mathrm{N}=326)$.

\begin{tabular}{lcccc}
\hline \multirow{2}{*}{$(\mathbf{N}=\mathbf{3 2 6})$} & \multicolumn{2}{c}{ Normal mental health } & \multicolumn{2}{c}{ Abnormal mental health } \\
\cline { 2 - 5 } & $\mathbf{n}$ & $\mathbf{\%}$ & $\mathbf{n}$ & $\mathbf{\%}$ \\
\hline Probable PTSD & 181 & 55.52 & 145 & 44.48 \\
Probable depression & 224 & 68.71 & 102 & 31.29 \\
Psychological distress & 230 & 70.55 & 96 & 29.45 \\
Alcohol abuse & 270 & 82.82 & 56 & 17.18 \\
Risk of suicide & 311 & 95.40 & 15 & 4.60 \\
\hline
\end{tabular}

The result of the binary analysis indicates that individuals with prior physical conditions $(\mathrm{OR}=$ $2.19,95 \% \mathrm{CI}=1.30-3.69, \mathrm{p}<0.01)$, perceived mental health impact $(\mathrm{OR}=2.80,95 \% \mathrm{CI}=2.02-3.90$, $\mathrm{p}<0.001)$, and upper respiratory infection after the flood $(\mathrm{OR}=1.75,95 \% \mathrm{CI}=1.02-2.99, \mathrm{p}<0.05)$ were more likely to report scores above the cut-off for probable PTSD compared with participants without these qualities. As for depression, persons of older age $(\mathrm{OR}=1.03,95 \% \mathrm{CI}=1.01-1.06 \mathrm{p}<$ $0.01)$, prior physical conditions $(\mathrm{OR}=2.19,95 \% \mathrm{CI}=1.30-3.69, \mathrm{p}<0.01)$, perceived mental health impact $(\mathrm{OR}=2.80,95 \% \mathrm{CI}=2.02-3.90, \mathrm{p}<.001)$, or skin infection after the flooding $(\mathrm{OR}=1.72,95 \%$ $\mathrm{CI}=1.01-2.94, \mathrm{p}<0.05)$ were more likely to report scores above the cut-off for depression compared with participants without these qualities. For psychological distress, individuals who perceived mental health impact after the flood $(\mathrm{OR}=3.58,95 \% \mathrm{CI}=2.42-5.28, \mathrm{p}<0.001)$ were more likely to report scores above the cut-off for psychological distress compared with participants without these qualities while individuals who had higher scores in social support were less likely to have psychological distress problems $51.70 \%(\mathrm{OR}=0.48,95 \% \mathrm{CI}=0.31-0.74, \mathrm{p}<0.01)$. For alcohol abuse, women $(\mathrm{OR}=0.02$, $95 \% \mathrm{CI}=0.00-0.14 \mathrm{p}<.001)$ were less likely to report scores above the cut-off for problems with alcohol while men were more likely to report alcohol problems than women by $98 \%$. At the same time, individuals who perceived themselves having minor health problems $(\mathrm{OR}=0.39,95 \% \mathrm{CI}=0.18-0.84 \mathrm{p}$ $<0.05$ ) were less likely to report problems with alcohol than those who were healthy by $61.50 \%$. An individual injured during the flood $(\mathrm{OR}=15.39,95 \% \mathrm{CI}=2.52-94.13, \mathrm{p}<0.01)$, or with a medical condition resulting from the flood $(\mathrm{OR}=47.11,95 \% \mathrm{CI}=7.87-282.18, \mathrm{p}<0.001)$, was more likely to have suicidal tendencies when compared to an individual without these conditions. However, an individual who had a higher score showing social support was less likely to be at risk of suicide by $66 \%$. 
Table 3 The binary logistic regression analysis of the effects of demographics, health conditions prior to and after the flood, physical trauma, mental health impact, and social support on the odds ratio of psychological distress, probable PTSD, probable depression, suicide risk and alcohol abuse in the flood survivors.

\begin{tabular}{|c|c|c|c|c|c|c|c|c|}
\hline & \multirow{2}{*}{ B } & \multirow{2}{*}{ S.E. } & \multirow{2}{*}{ Wald } & \multirow{2}{*}{ df } & \multirow{2}{*}{ Sig.* } & \multirow{2}{*}{ 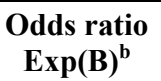 } & \multicolumn{2}{|c|}{$\operatorname{Exp}(B) 95 \%$ CI } \\
\hline & & & & & & & Lower limit & Upper limit \\
\hline \multicolumn{9}{|l|}{ Probable PTSD } \\
\hline Prior physical conditions & .78 & .27 & 8.77 & 1 & $.003 * *$ & 2.19 & 1.30 & 3.69 \\
\hline Perceived mental health impacted & 1.03 & .17 & 37.86 & 1 & $.000 * * *$ & 2.80 & 2.02 & 3.90 \\
\hline Upper respiratory infection after the flood & .56 & .27 & 4.19 & 1 & $.041 *$ & 1.75 & 1.02 & 2.99 \\
\hline \multicolumn{9}{|l|}{ Probable depression } \\
\hline Age & .03 & .012 & 7.60 & 1 & $.006^{* *}$ & 1.03 & 1.01 & 1.06 \\
\hline Prior physical conditions & .72 & .30 & 5.97 & 1 & $.015^{*}$ & 2.06 & 1.16 & 3.69 \\
\hline Perceived mental health impacted & .99 & .19 & 28.52 & 1 & $.000 * * *$ & 2.70 & 1.88 & 3.89 \\
\hline Skin infection after the flood & .54 & .27 & 3.93 & 1 & $.048^{*}$ & 1.72 & 1.01 & 2.94 \\
\hline \multicolumn{9}{|l|}{ Psychological distress } \\
\hline Perceived mental health impacted & 1.27 & .20 & 41.20 & 1 & $.000 * * *$ & 3.58 & 2.42 & 5.28 \\
\hline Social support & -.73 & .22 & 10.92 & 1 & $.001 * *$ & .48 & .31 & .74 \\
\hline \multicolumn{9}{|l|}{ Alcohol abuse problem } \\
\hline Women & -3.93 & 1.02 & 14.90 & 1 & $.000 * * *$ & .02 & .00 & .14 \\
\hline Perceived minor health problems & -.96 & .40 & 5.80 & 1 & $.016^{*}$ & .39 & .18 & .84 \\
\hline Perceived chronic health problems & -1.26 & 1.10 & 1.33 & 1 & .249 & .29 & .03 & 2.42 \\
\hline \multicolumn{9}{|l|}{ Risk of suicide } \\
\hline Social support & -1.08 & .33 & 10.89 & 1 & $.001 * *$ & .34 & .18 & .65 \\
\hline Injury during the flood & 2.73 & .92 & 8.76 & 1 & $.003 * *$ & 15.39 & 2.52 & 94.13 \\
\hline Health problems caused from the flood & 3.85 & .913 & 17.80 & 1 & $.000^{* * *}$ & 47.11 & 7.87 & 282.18 \\
\hline
\end{tabular}

\section{Discussion}

Our research team set out to find the prevalence and factors relating to psychological distress, probable PTSD, probable depression, risk of suicide and problems of alcohol abuse of survivors 4 to 6 months after the floods. The results of this study were compared with previous studies based on a Thai population such as Boonyamalik et al. who used not only self-reporting questionnaires but also the Diagnostic and Statistical Manual of Mental Disorders, 4th Edition, (DSM-IV criteria). They found a prevalence rate of PTSD, major depressive disorder, problems with alcohol and suicide risk as 15, 79, 25 and $1 \%$ respectively. A study of predictors of adverse emotional responses to flooding in Hat Yai, southern Thailand found $40 \%$ of the respondents had a positive GHQ-12 score suggesting mental health problems [7]. However, they collected data from a different age range of participants which included participants aged 14 and over. Additionally, the timeline of data collection was in the direct aftermath of the floods. From studies of psychological impact of flooding elsewhere in the world, Paranjothy et al. in England found the prevalence rate of psychological distress, probable depression, probable PTSD as 69, 43 and $22 \%$ respectively. However, their study used mixed mailing questionnaires sent to the participants and face to face methods in data collection. Thus, it should be pointed out that the differences of the prevalence rate of mental health problems after these various floods may be due to diverse aspects such as assessment methodology, research tools, participant age group, severity and damage resulting from the flood, and the timing of investigation after the flood. Mason also supported using self-reporting in data collection to determine that the prevalence rate is higher when compared to clinical diagnosis [26].

In order to explain factors affecting the prevalence of mental health problems after flooding, these were categorized in 2 aspects: risk factors and protective factors as discussed above. Risk factors related to mental health problems included age, prior physical conditions, perceived impact on mental health, respiratory and skin infection, health problems caused by the flood and injuries during the flood. 
Protective factors were social support provided, minor health problems and being of the female gender. This study is in line with previous studies that show the relationship between age and the prevalence of PTSD and depression such as a study in India which found that individuals over the age of 60 years had significantly higher scores for PTSD and depression compared to all other groups [30]; this was consistent with studies in China [1] and Thailand [31]. Previous studies also support that having a prior physical condition was related to the prevalence of PTSD [11,27,32], and psychological distress [26] after the flood. For individuals injured during the flood, previous studies of the Thai population studied found a higher prevalence rate of PTSD and depression in persons who had been injured during a tsunami [31] and a longitudinal study in Southern Thailand support that individuals who suffered from physical injury after the flood were less likely to recover from PTSD [6]. Our study was congruent with a study of a Chinese population which found that physical injury during a natural disaster was more likely to result in having severe PTSD [1].

As to problems of alcohol abuse, it was found that the risk factors were being male and a perception of good health. This result is consistent with the study of patterns of alcohol dependence in Thai drinkers that found the 1-year prevalence rates of alcohol dependence were $1.4 \%$ in women and $13.7 \%$ in men [33]. This study also similar to the study of a Vietnamese population that found the primary predictor of alcohol dependency was being of male gender [34]. However, a study in the United States found that women with symptoms of depression were more like to use alcohol to cope with disasters [35]. This may be due to individuals in good physical health using alcohol to cope with stressful situations or problems. Also, problems of alcohol abuse and PTSD have been found to be co-occurrent in previous studies [18], namely, that $20 \%$ of individuals with PTSD use alcohol, drugs, or both to reduce their symptoms.

The results also indicated that social support has a significantly positive and ameliorating effect on psychological distress and risk of suicide. Individuals who have higher levels of social support were 51.70 $\%$ less likely to experience psychological distress and $66 \%$ less likely to be at risk of suicide. This study is consistent with previous studies such as those of Dai et al. that found social support is one of the predictors of recovery from post-traumatic stress disorder [6] and Fernandez et al. which found that social support had an inverse relationship with mental distress [4]. In addition, Zhang et al. found that social support exerted a protective effect for suffering from probable PTSD, anxiety and depression [1]. In addition, Feng et al. claimed that subjective support and support utilization may play more important roles in mitigating the impact of flooding than objective support [36].

\section{Conclusions}

This study provided useful information for a better understanding of risk factors and the prevalence of psychological distress, PTSD, depression, suicide risk and alcohol abuse in survivors after the flood. Healthcare personnel should consider these survivors at high risk of PTSD, especially those who have had prior physical conditions, and those with physical injury or health problems caused by the floods and those who perceive mental health impact. People with depression were more likely to have skin infection after the flood and perceived mental health impact. Individuals who had psychological distress were more likely to perceive impact on their mental health. Meanwhile, males perceived in good health were more prone to have alcohol problems. Individuals with prior physical conditions and who were injured during the flood were at higher risk of suicide. The findings of this research suggested that social support played an important role as a significant protective factor mitigating psychological distress and suicidal risk of the survivors. Public health agencies and local healthcare organizations need to build emergency preparedness and response system to minimize the psychological and mental health impact of flooding.

Implications for future research, it is recommended that additional risk factors associated with other aspects of the flood in further research studies be investigated, such as features of the flood event, disasters preparedness policy, or intervention which might mitigate the adverse post-flood experience on the mental health and well-being of the survivors. 


\section{Limitations}

This study is limited in that it focused on one occurrence of a flood with flash flooding and a landslide in southern Thailand and that data was collected from 4 to 6 months after the flood. Therefore, if these same results were used to estimate mental health problems arising from flooding in a wider flood plain community or if a different timeline of data collection were followed, it would probably lead to differences of estimation of mental health problems and risk factors. Furthermore, we did not apply any independent criteria that would provide alternate diagnosis of any mental health problems but merely followed the guidelines of the interpretation set out in the questionnaire. Finally, this study used a crosssectional design to collect data examining individuals at a single point in time; therefore, causal relationships cannot be proven. In cross-sectional studies, it is not possible to ascertain the extent to which pre-flood mental health affected post-flood mental health. Thus, individuals with pre-flood mental health problems may have reported greater increases of these symptoms after the flood. Consequently, a longitudinal study methodology is necessary to examine the long-term mental health impact from flooding.

\section{Acknowledgements}

The authors wish to thank to all the participants affected by the floods who kindly participated in the study. We also express our thanks to the community leaders for their assistance during data collection. This research was funded by the Office of Higher Education Commission and Walailak University, Thailand.

\section{References}

[1] Z Zhang, W Wang, Z Shi, L Wang and J Zhang. Mental health problems among the survivors in the hard-hit areas of the Yushu earthquake. PLoS One 2012; 7, e46449.

[2] P Boonyamalik, S Suksawang and S Swangwongsin. A one-year cohort study in mental health problems of the flooding victims in Uttaradit, 2005. J. Psychiat. Assoc. Thai 2012; 57, 165-74.

[3] NK Channaveerachari, A Raj, S Joshi, P Paramita, R Somanathan, D Chandran, S Kasi, NR Bangalore and SB Math. Psychiatric and medical disorders in the after math of the Uttarakhand disaster: Assessment, approach, and future challenges. Indian J. Psychol. Med. 2015; 37, 138-43.

[4] A Fernandez, J Black, M Jones, L Wilson, L Salvador-Carulla, T Astell-Burt and D Black. Flooding and mental health: A systematic mapping review. PLoS One 2015; 10, 1-20.

[5] K Azuma, K Ikeda, N Kagi, U Yanagi, K Hasegawa and H Osawa. Effects of water-damaged homes after flooding: Health status of the residents and the environmental risk factors. Int. J. Environ. Res. Public Health 2014; 24, 158-75.

[6] W Dai, J Wang, AC Kaminga, L Chen, H Tan, Z Lai, J Deng and A Liu. Predictors of recovery from post-traumatic stress disorder after the Dongting lake flood in China: A 13-14 year follow-up study. BMC Psychiat. 2016; 16, 382.

[7] S Assanangkornchai, SN Tangboonngam and JG Edwards. The flooding of Hat Yai: Predictors of adverse emotional responses to a natural disaster. Stress Health 2004; 20, 81-9.

[8] G Blöschl, L Gaál, J Hall, A Kiss, J Komma, T Nester, J Parajka, RAP Perdigão, L Plavcová, M Rogger, JL Salinas and A Viglione. Increasing river floods: Fiction or reality? Wires Water 2015; 2, $329-44$

[9] AC Minervino and EC Duarte. Danos materiais causados à Saúde Pública e à sociedade decorrentes de inundações e enxurradas no Brasil, 2010-2014: Dados originados dos sistemas de informação global e nacional. Ciencia Saude Colet. 2016; 21, 685-94.

[10] L Kaizhong, W Shaohong, D Erfu and X Zhongchun. Flood loss analysis and quantitative risk assessment in China. Nat. Hazards 2012; 63, 737-60.

[11] S Paranjothy, J Gallacher, R Amlot, GJ Rubin, L Page, T Baxter, J Wight, D Kirrage, RM Naught and SR Palmer. Psychosocial impact of the summer 2007 floods in England. BMC Public Health 2011; 11, 145-52. 
[12] S Chakrabhand, B Panyayong and P Sirivech. Mental health and psychosocial support after the tsunami in Thailand. Int. Rev. Psychiat. 2006; 18: 599-605.

[13] S, Assanangkornchai, SN Tangboonngam, N Sam-angsri and JG Edwards. A Thai community's anniversary reaction to a major catastrophe. Stress Health 2007; 23, 43-50.

[14] P Udomratn. Mental health and the psychosocial consequences of natural disasters in Asia. Int. Rev. Psychiat. 2008; 20, 441-4.

[15] X Li, X Huang, H Tan, A Liu, J Zhou and $\mathrm{T}$ Yang. A study on the relationship between posttraumatic stress disorder in flood victim parents and children in Hunan, China. Aust. New Zealand J. Psychiat. 2010; 44, 543-50.

[16] B Bei, C Bryant, KM Gilson, J Koh, P Gibson, A Komiti, H Jackson and F Judd. A prospective study of the impact of floods on the mental and physical health of older adults. Aging Ment. Health 2013; 17, 992-1002.

[17] M Ahern, RS Kovats, P Wilkinson, R Few and F Matthies. Global health impacts of floods: Epidemiologic evidence. Epidemiol. Rev. 2005; 27, 36-46.

[18] M Leeies, J Pagura, J Sareen and JM Bolton. The use of alcohol and drugs to self-medicate symptoms of posttraumatic stress disorder. Depress. Anxiety 2010; 27, 731-6.

[19] LR Turner, K Alderman, C Huang and S Tong. Impact of the 2011 Queensland floods on the use of tobacco, alcohol and medication. Aust. New Zealand J. Public Health 2013; 37, 396.

[20] D Lowe, KL Ebi and B Forsberg. Factors increasing vulnerability to health effects before, during and after floods. Int. J. Environ. Res. Public Health 2013; 10, 7015-67.

[21] JE Lamond, RD Joseph and DG Proverbs. An exploration of factors affecting the long term psychological impact and deterioration of mental health in flooded households. Environ. Res. 2015; 140, 325-34.

[22] S Wichitnak, S Sintuprasit, P Saralook and J Padungyat. Risk factors causing persistence of stress after flood disaster stress in Ang-Thong Province. J. Health Syst. Res. 2007; 1, 181-7.

[23] C Tanavud, C Yongchalermchai and A Bennui. An assessment of floods risks in Southern Thailand. J. Rem. Sen. GIS Assoc. Thai 2004; 5, 10-21.

[24] S Khoaphuthai. Communicable Disease in Flooding Areas. Nonthaburi: Health Information System Development Office (HISO). Available at: http://www.hiso.or.th/hiso/tonkit/tonkits_13.php, accessed December 2016.

[25] P Phutmongkhon, S Yongsatisak, A Khampeera, C Yongchalermchai, N Jungcharoentham and R Tongyoi. Application of remote sensing technology and geographic information system to allocate the flood hazard areas in the upper eastern area of southern Thailand. J. Rem. Sen. GIS Assoc. Thai 2005; 6, $1-10$.

[26] V Mason, H Andrews and D Upton. The psychological impact of exposure to floods. Psychol. Health Med. 2010; 15, 61-73.

[27] X Zhou, L Kang, X Sun, H Song, W Mao, X Huang, Y Zhang and J Li. Prevalence and risk factors of post-traumatic stress disorder among adult survivors six months after the Wenchuan earthquake. Compr. Psychiat. 2013; 54, 493-9.

[28] J Sonpaveerawong and N Chuwichian. Health impact, perceptions, adaptations and social support among people in flash floods and mudslide in Sichon district, Nakhon Si Thammarat province. Songklanagarind Med. J. 2015; 33, 109-19.

[29] K Penglong and D Lalitanantpong. Mental health and post-traumatic stress symptoms related to combat in soldiers at Phramongkutklao Hospital. Chulalongkorn Med. J. 2016; 60, 329-53.

[30] S Telles, N Singh and M Joshi. Risk of posttraumatic stress disorder and depression in survivors of the floods in Bihar, India. Indian J. Med. Sci. 2009; 63, 330-4.

[31] F Griensven, ML Chakkraband, W Thienkrua, W Pengjuntr, BC Lopes, P Tantipiwatanaskul, PA Mock, S Ekassawin, A Varangrat, C Gotway, M Sabin and JW Tappero. Mental health problems among adults in tsunami-affected areas in southern Thailand. J. Am. Med. Assoc. 2006; 296, 537-48.

[32] K Alderman, JR Turner and S Tong. Assessment of the health impacts of the 2011 summer floods in Brisbane. Disast. Med. Public Health Prep. 2013; 7, 380-6. 
[33] M Srisurapanont, $\mathrm{P}$ Kittiratanapaiboon, $\mathrm{S}$ Likhitsathian, $\mathrm{T}$ Kongsuk, $\mathrm{S}$ Suttajit and $\mathrm{B}$ Junsirimongkol. Patterns of alcohol dependence in Thai drinkers: A differential item functioning analysis of gender and age bias. Addict. Behav. 2012; 37, 173-8.

[34] Pollack, B Weiss and LT Trung. Mental health, life functioning and risk factors among people exposed to frequent natural disasters and chronic poverty in Vietnam. BJPsych Open 2016; 2, 22132.

[35] SR Lowe, L Sampson, MN Young and S Galea. Alcohol and nonmedical prescription drug use to cope with posttraumatic stress disorder symptoms: An analysis of hurricane Sandy survivors. Subst. Use Misuse 2017; 52, 1348-56.

[36] S Feng, H Tan, A Benjamin, S Wen, A Liu, J Zhou, S Li, T Yang, Y Zhang, X Li and G Li. Social support and posttraumatic stress disorder among flood victims in Hunan, China. Ann. Epidemiol. $2007 ; \mathbf{1 7}, 827-33$. 